\title{
Youth Beliefs About Health and Physical Activity
}

\author{
BRUCE WATKINS \\ University of Michigan
}

\begin{abstract}
This study examined the extent to which youth at Grades 3, 6, 9, and 12 believed that frequent physical activity resulted in various physical and psychological outcomes. Youth at all four ages believed that frequent activity resulted in beneficial physical outcomes. Younger respondents were more likely to affirm external physical outcomes than either internal physiological or psychological outcomes. Older adolescents were more likely than children to affirm internal physiological outcomes. In contrast to prediction, adolescents were less likely than children to affirm psychological outcomes. The study also assessed beliefs about the effect of various harmful behaviors (e.g., smoking, drug use, lack of exercise) on physical fitness and ability. Abusive behaviors (e.g., smoking, drinking) were judged to be more harmful to physical ability than were sedentary behaviors (e.g., not exercising).
\end{abstract}

Exercise and physical activity are important components of childhood, and are thought to be beneficial to both the physical health and psychological well-being of the developing individual (Haskell, Montoye, \& Orenstein, 1985). There is also evidence that amount of physical activity in childhood is related to both physical-activity level and health during adulthood (Dennison, Straus, Mellits, \& Charney, 1988; Powell \& Dysinger, 1987). The preschool and elementary years provide ample opportunities for children to engage in unstructured physical activities, either alone or with peers (e.g., walking, running, bicycle riding, swimming). Many children — both boys and girls - also participate in organized athletic activities during the elementary-school years and beyond.

There are multiple motives for participating in sports and physical activity during childhood and adolescence, including enjoyment, opportunity for social interactions, enhancement of self-esteem, and peer or parental pressures. The beneficial impact of activity on health and fitness is a possible reason for participation as well. It is likely that this reason becomes more important with age: Anticipated health-related benefits have been shown to be related to adult par-

I thank the cooperating 3rd-, 6th-, 9th-, and 12th-grade teachers at Haisley, Lawton, Northside, Tappan, Slauson, and Huron schools, and especially their students, for their participation. Amy Montgomery contributed to all phases of the study. This research was supported by a Faculty grant awarded by the Horace Rackham School of Graduate Studies at the University of Michigan, whose support is gratefully acknowledged.

Correspondence and requests for reprints should be sent to Bruce Watkins, Department of Sports Management and Communication, 3060 CCRB, University of Michigan, Ann Arbor, MI 48109. 
ticipation (Dishman, 1987; Dishman, Sallis, \& Orenstein, 1985; Telama, Voulle, \& Laasko, 1981), especially among samples with chronic or acute health problems (Becker, 1979). However, research in this area also suggests that, among adults, increased knowledge about positive health benefits of exercise and activity does not necessarily lead to increased physical activity (Dishman et al., 1985).

Although evidence points to a relationship between physical activity and various physical (e.g., cardiovascular conditioning, strength, endurance) and psychological (e.g., positive self-image) outcomes (Blair, Jacobs, \& Powell, 1985; Folkins \& Sime, 1981; Siscovick, LaPorte, \& Newman, 1985; Taylor, Sallis, \& Needle, 1985), sparse evidence is available that details whether or when children and adolescents recognize these relationships. In particular, it is not clear how these beliefs change with age. Such information might prove valuable to establishing or motivating participation in physical activities during childhood and early adolescence. Continued participation in activities at these ages seems particularly important in light of recent evidence that a number of adult diseases (e.g., coronary heat disease) appear to have their genesis early in childhood (Haskell et al., 1985) and that the overall physical conditioning of American youth is declining (Duncan, Boyce, Itgami, \& Paffenbarger, 1983; Sallis, 1987).

What is known about youth health-related beliefs comes primarily from research on developing knowledge about body structure and function (Crider, 1981; Gellert, 1962; Nagy, 1953), about general health (Dielman et al., 1980; Gochman, 1971; Godin \& Shephard, 1984; Natapoff, 1982), or, especially, about illness (Bibace \& Walsh, 1981; Burbach \& Peterson, 1986). In general, the latter research has revealed a progression in understanding the causes and consequences of illness that is correlated with either age (see Peters, 1978) or performance on measures of cognitive development (see Bibace \& Walsh, 1979; Burbach \& Peterson, 1986). Younger children (classified as preoperational) recognize and report single external physical manifestations of illness but are unable to articulate the relationship between the source of the illness and the illness itself. During concrete operations children begin to define illness in terms of multiple "externally visible bodily processes" (Bibace \& Walsh, 1979, p. 293), and begin to understand causal links between the source of the illness and the effects on the body. With the onset of formal operations there is an increasing awareness of internal, physiological relationships. Finally, older adolescents and adults also understand that physical conditions are linked to a variety of psychological states (Bibace \& Walsh, 1979; Burbach \& Peterson, 1986).

There are three important and unanswered questions in the development of knowledge about outcomes of physical activity: (a) To what extent do children and adolescents perceive ties between participation in physical activities and various beneficial physical and psychological outcomes? (b) Do these beliefs change predictably with age? and (c) Do beliefs about various relationships help 
either to establish and maintain physical activity, or to increase its level, across childhood and adolescence?

The present study addressed the first two questions. It investigated knowledge among children and adolescents about the consequences-both physiological and psychological-of frequent physical activity. Response patterns were predicted based generally on stages of cognitive and social-cognitive (Shantz, 1983) development. I believed that younger respondents would be as likely as older respondents to identify external physical outcomes of activity. However, I predicted that older respondents would be more likely than younger respondents to affirm both internal physical (Hypothesis 1a) and psychological outcomes (Hypothesis 1b). Further, I predicted that among younger respondents, external physical outcomes would be affirmed more frequently than would either internal physical (Hypothesis 2a) or psychological outcomes (Hypothesis $2 b$ ).

A related component of knowledge about physical activity is beliefs about behaviors that might be harmful to one's ability to be physically active. Indeed, most youth receive a variety of formal and informal messages that educate them in the dangers posed to health by abusive behaviors such as smoking, drug use, and alcohol abuse (Chassin, Presson, Sherman, \& McGrew, 1987; Eiser, Walsh, \& Eiser, 1986; Evans et al. 1978; Gaines, Brooks, Maisto, Dietrich, \& Shagena, 1988). More recently, an inactive lifestyle during childhood has been linked to poorer physical and physiological conditioning as well (Dietz \& Gortmaker, 1985; Haskell et al., 1985). Thus, a final goal of this study was to assess youth beliefs about the impact of a variety of abusive and sedentary behaviors on physical ability and activity level. Because of the exploratory nature of this part of the study, no hypotheses were formed.

\section{METHOD}

\section{Subjects}

As participants for the interviews, 229 youth at Grades 3, 6, 9, and 12 were recruited from classrooms in three elementary schools, two junior high schools, and one senior high school. All had parental permission. Age and sex distributions were: 46 boys and 35 girls ( $M=8$ years, 8 months) in the 3rd grade, 28 boys and 31 girls $(M=11$ years, 7 months) in the 6th grade, 22 boys and 20 girls ( $M=14$ years, 10 months) in the 9 th grade, and 21 boys and 26 girls $(M=17$ years, 11 months) in the 12 th grade.

\section{Procedure}

There were 83 items in the complete interview. Nine were open-ended and 72 were forced-choice questions. Two asked for estimates of perceived physical ability. Each youth participated in a one-on-one interview with one of four ( 2 men, 2 women) interviewers. Approximately equal numbers of same- and op- 
posite-sex interviews were conducted. Interviewers read each item to participants in Grades 3 and 6; open-ended items were read to subjects in Grades 9 and 12, who subsequently read and completed the forced-choice items individually.

The instrument was extensively piloted prior to data collection to ensure that all words, concepts, and instructions were comprehensible to respondents. Questions were worded to be understandable to the youngest group of respondents, and results of piloting indicated that items were generally understood by youth at first and second grades. There were very few instances during data collection when a respondent would inquire about the meaning of an item or question (e.g., Experimenter: "When people play sports a lot, do they think they're a better or nicer person?" Respondent: “Do you mean are they happier?"). In these cases interviewers repeated the item and indicated its sense was "whatever it means to you."

\section{Measures}

Outcomes of Physical Activity. The first part of the questionnaire focused on qualities that contributed to athletic excellence and distinguished excellent athletes from others. Results from this are presented elsewhere (Watkins \& Montgomery, 1989). The second section assessed knowledge about the outcomes of physical activity. A list of behaviors was presented, and respondents were asked whether each was a likely outcome of frequent physical activity. The exemplars were selected from the literature as established outcomes of physical activity (Blair et al., 1985; Haskell et al., 1985; Siscovick et al., 1985). They were chosen from external physical outcomes (i.e., three items: get stronger, bigger muscles, change in body size), internal physical outcomes (i.e., nine items: longer muscles, stronger heart, bigger lungs, higher body temperature, loss of internal fat, increased energy, increased lung capacity, increased volume of blood pumped by heart, change in appetite), and psychological outcomes (i.e., four items: more relaxed, better self-image, improved learning, improved attention skills). Respondents were instructed to make minimal use of "maybe" responses, and to restrict "don't know" responses to situations where they really were unsure. Three scores per subject represented the ratio of the total number of "yes" responses per outcome type to the total possible. "Maybe" and "it depends" were counted as "yes" responses. "Don't know" and "no" responses were combined. Results from data analyses were the same whether such qualifying responses were included or excluded. Cronbach standardized alphas obtained for the three outcome types were $.43, .62$, and .48 , for external physical, internal physical, and psychological outcomes, respectively.

Harmful Activities. The final section of the questionnaire was intended to assess beliefs about the potential harm of a variety of behaviors to general physical ability and fitness. Respondents were presented with a list of behaviors 
and were asked whether physical ability could be harmed if a person engaged in each behavior. Activities were chosen to represent abusive behavior (i.e., five items: smoking cigarettes, drinking whiskey, drinking beer, overeating, taking drugs) ${ }^{1}$ or sedentary behavior (i.e., five items: sitting around a lot, sleeping too much, not exercising, watching too much television, not practicing at sports). ${ }^{2}$ Again, two scores represented the ratio of the total "yes" responses to the total possible in each category. Cronbach standardized alphas were .63 (abusive) and .35 (sedentary), indicating considerable variability in responses to sedentary items. $^{3}$

\section{RESULTS}

\section{Outcomes of Physical Activity}

A $4 \times 2 \times 3$ analysis of variance (ANOVA) was performed on the three ratio scores. Grade $(3,6,9,12)$ and sex (male, female) were between-group factors and outcome type (external physical, internal physical, psychological) was a within-subject factor. $T$ tests were used for analyzing significant effects involving independent samples; Tukey $B$ was used for within-group comparisons.

The analysis showed significant main effects for sex, $F(1,221)=18.93, p<$ .0001 , and for outcome type, $F(2,442)=84.82, p<.0001$. Boys were more likely than girls to agree that the exemplars were outcomes of physical activity $(M=.69$ vs. .59$)$. Respondents affirmed both physical outcomes more often than psychological outcomes $(p<.01$, each comparison).

Interactions of outcome type with grade, $F(6,442)=5.27, p<.0001$, and outcome type with grade and sex, $F(6,442)=2.11, p=.05$, were significant. Means for the two-way interaction are presented in Table 1 (p. 262), and means for the three-way interaction are diagrammed in Figure 1 (p. 263).

As can be seen in Table 1, affirmation of external physical outcomes was equivalent at all ages. Affirmation of internal physical outcomes increased with age (confirming Hypothesis 1a). Respondents at Grade 12 were significantly

I "Drinking milk" was included in the original item list to guard against response set. All but one subject indicated it was not detrimental to ability.

${ }^{2}$ The qualifiers "too much" and "a lot" were added to communicate excesses in these behaviors. The links between specific sedentary behaviors and poor health and conditioning are less clear than those of abusive behaviors. For example, although television has been blamed for its contribution to poor physical conditioning in childhood (Dietz \& Gortmaker, 1985; Tucker, 1986), it is possible that a child who is quite active physically might continue to view too much TV. Nevertheless, it remains important to understand whether the youth themselves perceive these relationships.

${ }^{3}$ This was due primarily to two items. Only about one in three believed that sleeping too much (37\%) or watching too much television (35\%) could harm physical ability. However, over $80 \%$ of respondents indicated that sitting around a lot $(81 \%)$, not exercising $(95 \%)$, and not practicing at sports (97\%), could be harmful. In contrast, judgments about abusive behaviors were consistently high: overeating $(79 \%)$, smoking cigarettes $(93 \%)$, drinking whiskey $(94 \%)$, drinking beer $(85 \%)$, and taking drugs $(99 \%)$. 
TABLE 1

Mean Ratio Score for Each Outcome Type, by Grade

\begin{tabular}{rccc}
\hline & \multicolumn{3}{c}{ Outcome Type } \\
\cline { 2 - 4 } Grade & External Physical & Internal Physical & Psychological \\
\hline 3 & $.73_{\mathrm{a}}$ & $.61_{\mathrm{b}}$ & $.59_{\mathrm{b}}$ \\
6 & $.76_{\mathrm{a}}$ & $.63_{\mathrm{b}}$ & $.49_{\mathrm{c}}$ \\
9 & $.81_{\mathrm{a}}$ & $.66_{\mathrm{b}}$ & $.47_{\mathrm{c}}$ \\
12 & $.79_{\mathrm{a}}$ & $.74_{\mathrm{a}}$ & $.42_{\mathrm{c}}$ \\
$M$ & .77 & .65 & .51 \\
\hline
\end{tabular}

Note. For boys and girls, respectively: Grade $3, n=46$ and 35; Grade 6 , $n=28$ and $31 ;$ Grade $9, n=22$ and $20 ;$ Grade $12, n=21$ and 26. Within grades, means not sharing subscripts are significantly different from each other at $p<.01$.

more likely to affirm internal physical outcomes than were respondents at Grade $3, t(126)=3.82, p<.001 ;$ Grade $6, t(104)=3.32, p<.005$; and Grade 9 , $t(87)=2.01, p<.05$. Also according to prediction, younger respondents were more likely to affirm external versus other outcomes (Hypotheses $2 a, 2 b$ ). Respondents at Grades 3, 6, and 9 specified external physical outcomes significantly more than they did internal physical or psychological outcomes $(p<.01$, each comparison). However, adolescents at Grade 12 also affirmed external physical outcomes significantly more than psychological outcomes $(p<.01)$. Indeed, in contrast to prediction, beliefs about psychological outcomes of activity decreased with age (disconfirming Hypothesis $1 \mathrm{~b}$ ).

The three-way interaction points to different patterns of beliefs held by boys and girls at the four ages, as seen in Figure 1. In general, younger boys were more likely to affirm both internal physical and psychological outcomes than were younger girls. Boys were more likely to affirm internal physical outcomes at Grade $3(M=.67$ vs. .54$), t(79)=3.22, p<.005$; Grade $6(M=.70$ vs. $.57), t(57)=3.34, p<.005 ;$ and Grade $9(M=.73$ vs. .58$), t(40)=2.55, p<$ .025 . Similar differences between boys and girls were obtained in beliefs about psychological outcomes at Grade $3(M=.65$ vs. .50$), t(79)=2.31, p<.025$; and Grade $6(M=.63$ vs. .35$), t(57)=4.02, p<.001$. The difference at Grade 9 was not significant $(M=.52$ vs. $.41, p=.31)$. In contrast, adolescent boys and girls did not differ in beliefs about these two outcome types, but older boys were more likely than older girls to affirm external physical outcomes $(M=.87$ vs. $.73, p=.05$ ).

\section{Harmful Activities}

The ratio scores were subjected to a $4 \times 2 \times 2$ ANOVA. Grade $(3,6,9,12)$ and sex (male, female) were between-group factors, and behavior type (abusive, sedentary) was a within-subject factor. $T$ tests were used for mean comparisons. 

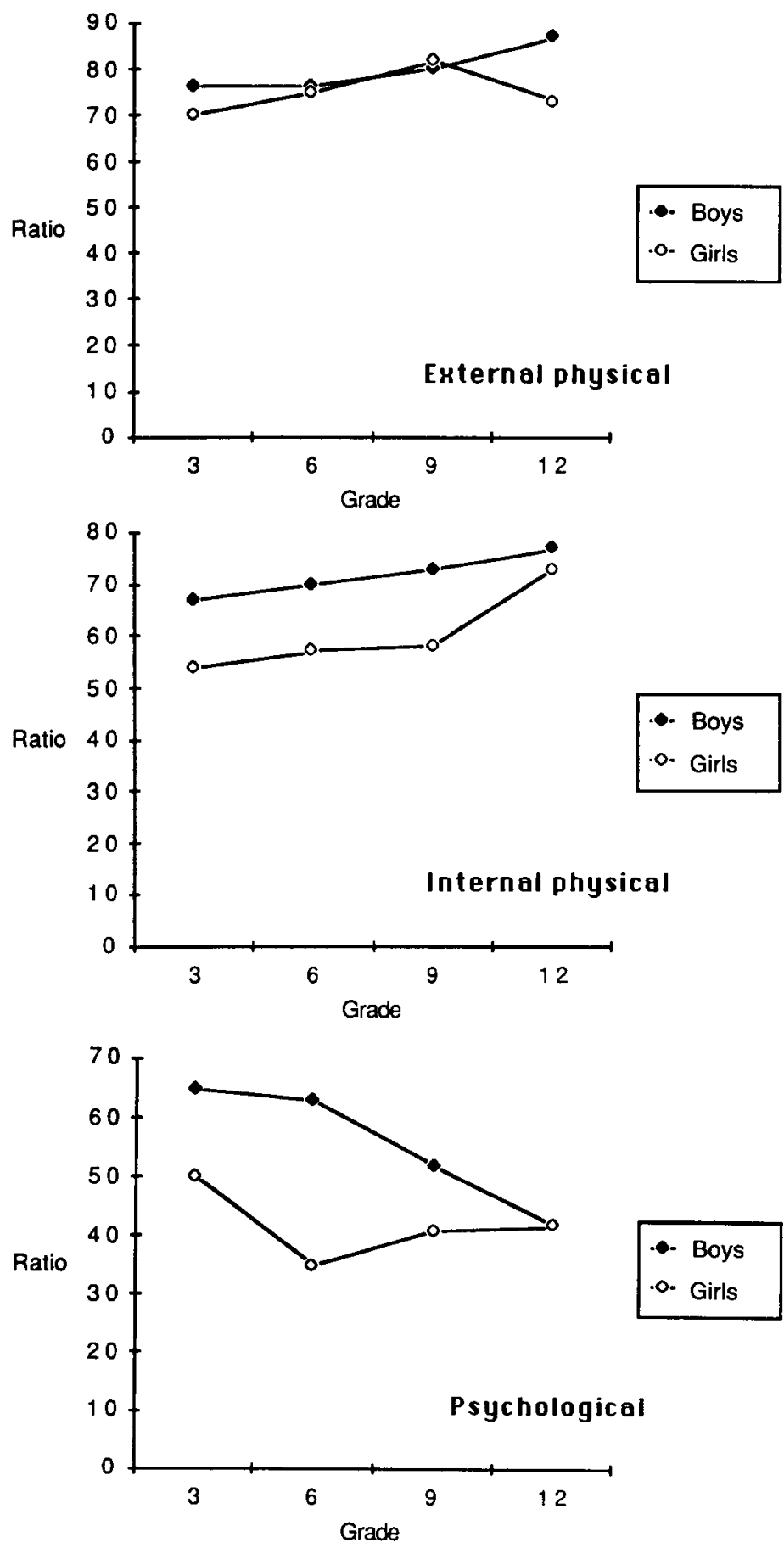

Figure 1. Mean outcome ratio score, by grade and sex. 


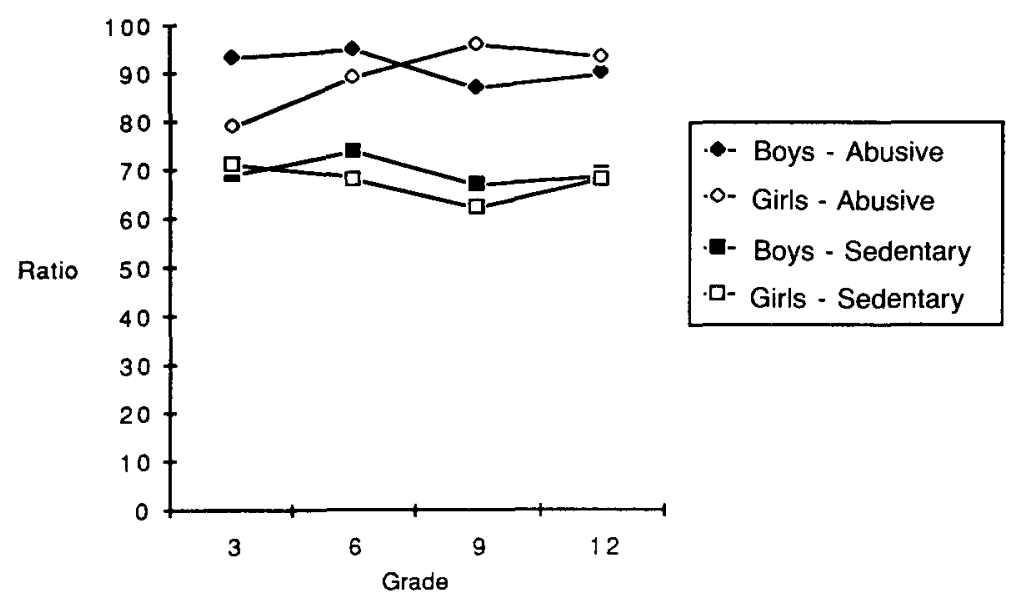

Figure 2. Mean ratio of harmful behaviors affirmed, by grade and sex.

The analysis revealed a significant main effect for behavior type, $F(1,221)=$ $193.93, p<.0001$. Abusive behaviors were perceived as potentially more detrimental than were sedentary behaviors $(M=.90$ vs. .69).

The interaction of behavior type, grade, and sex was significant, $F(3,221)=$ $4.26, p<.01$, and is presented in Figure 2. Among boys, abusive behaviors were consistently judged as significantly more harmful than were sedentary behaviors. Further, there were no age-related differences in judgments within behavior categories.

Among girls, the difference between Grades 3 and 9 in judgments about the impact of sedentary behaviors approached significance $(M=.71$ vs. $.62, p=$ .15). However, older girls judged abusive behaviors as significantly more harmful than did younger respondents. Significant differences were observed between Grade 3 girls $(M=.79)$, and those at both Grade $9(M=.96), t(53)=$ $2.68, p<.01$; and Grade $12(M=.93), t(59)=2.36, p<.025$. Sixth-grade girls were intermediate $(M=.89)$. As can be seen from Figure 2, as a group, 3rdgrade girls were least likely to judge abusive behaviors as harmful.

\section{DISCUSSION}

In terms of outcomes of frequent physical activity, three of the four hypotheses received significant support. Children were as likely as older respondents to identify external physical outcomes. Older adolescents were more likely than children to affirm internal physiological consequences of physical activity. Younger respondents were more likely to believe that physical activity resulted in observable physical outcomes than in either internal physiological or psychological outcomes.

These results fit well with other findings in the area of youth knowledge about health and illness. For younger children, the most salient outcomes are those that 
are visible and that can be linked easily to activities. As anticipated, the oldest respondents were more likely than younger children to believe that physical activity had benefits to physiological conditioning as well. Two factors probably account for this finding. First, younger children's concepts of the internal structure and functioning of the body is still relatively undeveloped. For example, Crider (1981, pp. 54, 57), relying on open-ended questions, found a rather low level of understanding of internal functioning by both 7-year-olds (e.g., heart is "for love," "if you didn't have a heart, you wouldn't be alive"), as well as some 9-year-olds (e.g., "the heart is what you breathe in . . your heart moves your stomach").

Second, even though a better understanding of physiology might be assumed by middle childhood, the linking of internal outcomes to external activities appears rather tenuous. A complete understanding of relationships-what has been termed "activity-related fitness" (Casperson, Powell, \& Christenson, 1985) - was not apparent in our middle-childhood respondents. Beliefs about physical outcomes held by respondents at 6 th grade were not significantly different from those of 3rd graders. Similarly, Bibace and Walsh (1979, pp. 294-295) indicated that younger children show poorer understanding of the causal factors related to physiological problems (e.g., heart attacks are caused by "lifting heavy stuff") than do adolescents (e.g., heart attacks occur "when the valves keep the blood from getting to the heart").

In contrast to prediction, adolescents were less likely than children to affirm psychological outcomes of activity. Perhaps there might be general agreement among adolescents that physical activity is good for psychological health, but no agreement about the factors that comprise psychological health. For example, Natapoff (1982) found that adolescents were more likely than children to correlate mental health with physical health, but less likely than children to correlate specific mental-health components with physical health (i.e., "feel good," "be happy").

It is also possible that youth, particularly adolescents, viewed several of these characteristics as opposites of physical activity-related outcomes. Examination of the responses to the four items reveals that the majority of adolescents believed that neither improved self-image, improved attention, nor improved learning, were direct correlates of physical activity. Spontaneous comments by the older respondents, in particular, focused on the latter two outcomes as academic skills, which were viewed as mutually exclusive of physical activity or ability. Nevertheless, this result is somewhat puzzling given the findings of various surveys of adults who consistently indicate that psychological outcomes similar to those we tested (e.g., enhanced feeling of well-being, improved self-image) are linked to regular physical activity (Brooks, 1989; cf. Folkins \& Sime, 1981).

The differences in beliefs between the sexes are intriguing, and may be related to differences in physical performance of boys and girls. Indeed, it is generally established that sex differences in a variety of physical behaviors and preferences 
appear early in childhood (see review in Maccoby \& Jacklin, 1978). Significant performance differences have led to different national norms for boys and girls as young as 6-years-old on fitness performance tasks such as sit-and-reach, pullups, sit-ups, and distance walking and running (Reiff et al., 1986; Ross, Pate, Delpy, Gold, \& Svilar, 1987). As young girls compare their abilities with those of boys, these performance differences may also have consequences in, among other factors, athletic self-confidence (Corbin, Landers, Feltz, \& Senior, 1983; Vealey, 1988), performance expectancies (Corbin et al., 1983; Duquin, 1986), perceived competence (Horn \& Hasbrook, 1986; Rudisill, 1988), and affect associated with physical activity (Coles, 1980). It is conceivable that overall evaluations of the beneficial outcomes of physical activity could be similarly affected.

Beliefs of 12th-grade girls were similar to those of older boys, except in terms of external physical outcomes, where they were less likely than boys to perceive frequent physical activity as correlated (i.e., to strength or muscle size). Indeed, it is probably true that in fitness-related activities at this age, size and strength is more important and more evident in typical male pursuits (e.g., football, basketball, weight lifting) than in gender-neutral activities (e.g., tennis, running). As noted, however, older boys and girls did not differ in their evaluation of activity's contributions to cardiovascular and endurance conditioning (i.e., internal physical outcomes), nor in their beliefs about psychological outcomes.

Knowledge itself may not be enough to effect behavior changes or to motivate continued participation in physical activities (see review by Stone, Perry, \& Luepker, 1989). For example, Dielman et al. (1980) indicated that adolescents were both more knowledgeable and less concerned about health issues than were children. They also reported that fully half of their sample of 6- to 17-year-olds engaged in some measure of dysfunctional health behaviors, apparently independent of level of health knowledge. Similar conclusions have resulted from a number of studies with adult samples (Dishman et al., 1985). Indeed, as other factors become more important to adolescents (e.g., perceived lack of physical competence, social comparison, or pressure to engage in other activities), the positive benefits of activity may seem irrelevant or unimportant. This appears to be the case by adulthood, when estimates indicate that $45 \%$ of adults fail to exercise at all (Dishman, 1987), and only 10\% are active at the recommended exercise level (Brooks, 1988).

Beliefs about the kinds of activities that could be harmful to physical abilities were quite consistent even among the youngest respondents, especially for behaviors classified as abusive to health. Such activities were uniformly assessed as more threatening than were sedentary activities. It is clear that most respondents believed that both types of behaviors have negative health and fitness implications. The low estimation of the danger of abusive behaviors by young girls is puzzling, however, and no explanation is readily apparent. This finding is not the result of performance on one or two items. Third-grade girls were less likely to 
believe in the harmful effects of overeating ( $66 \%$ of Grade 3 girls vs. $81 \%$ of all other respondents), smoking ( $80 \%$ vs. $95 \%$ ), and drinking either whiskey ( $83 \%$ vs. $96 \%$ ) or beer ( $69 \%$ vs. $88 \%$ ). Judgments about the potential harm of drug use were equivalent ( $97 \%$ vs. $99 \%$ ).

In contrast to the tenuous relationship between knowledge and physical activity, the relationship between knowledge about harmful behaviors and behavior in childhood and adolescence is generally strong. This is particularly true in terms of beliefs about substance abuse. For example, education through school curricula and mass media appears to have significantly affected attitudes toward and instances of drunk driving (Smith \& Remington, 1989). Similarly, drug education appears to have significantly altered youth attitudes about, and use of, drugs such as cocaine (Bachman, Johnston, \& O'Malley, 1990). Perhaps a similar emphasis on continued education about the beneficial outcomes of physical activity might ultimately contribute to strengthening the relationship between knowledge and physical activity as well.

\section{REFERENCES}

Bachman, J., Johnston, L., \& O'Malley, P. (1990). Explaining the recent decline in cocaine use among young adults: Further evidence that perceived risks and disapproval lead to reduced drug use. Journal of Health and Social Behavior, 31, 173-184.

Becker, M. (1979). Psychosocial aspects of health-related behavior. In H. Freeman, S. Levine, \& L. Reeder (Eds.), Handbook of medical sociology (pp. 253-274). Englewood Cliffs, NJ: Prentice-Hall.

Bibace, R., \& Walsh, M. (1979). Developmental stages in children's conceptions of illness. In G. Stone, F. Cohen, \& N. Adler (Eds.), Health psychology (pp. 285-301). San Francisco: Jossey-Bass.

Bibace,-R., \& Walsh, M. (Eds.). (1981). Children's conceptions of health, illness, and bodily functions. San Francisco: Jossey-Bass.

Blair, S., Jacobs, D., \& Powell, K. (1985). Relationship between exercise or physical activity and other health behaviors. Public Health Reports, 100, 172-180.

Brooks, C. (1988). Adult physical activity behavior: A trend analysis. Journal of Clinical Epidemiology, 4I, 385-392.

Brooks, C. (1989). A market segmentation analysis of adults according to self-reported interest in a regular program of exercise. Unpublished manuscript, Department of Sports Management and Communication, The University of Michigan, Ann Arbor.

Burbach, D., \& Peterson, L. (1986). Children's concepts of physical illness: A review and critique of the cognitive-developmental literature. Health Psychology, 5, 307-325.

Casperson, C., Powell, K., \& Christenson, G. (1985). Physical activity, exercise, and physical fitness: Definitions and distinctions of health-related research. Public Health Reports, 100. 126-131.

Chassin, L., Presson, C., Sherman, S., \& McGrew, J. (1987). The changing smoking environment for middle and high school students: 1980-1983. Journal of Behavioral Medicine, 10, 581593.

Coles, E. (1980). Sport in schools: The participation of girls. Sydney: New South Wales State Ministry of Education.

Corbin, C., Landers, D., Feltz, D., \& Senior, K. (1983). Sex differences in performance estimates: 
Female lack of confidence vs. male boastfulness. Research Quarterly for Exercise and Sport, $54,407-410$.

Crider, C. (1981). Children's conceptions of the body interior. In R. Bibace \& M. Walsh (Eds.), Children's conceptions of health, illness, and bodily functions (pp. 49-65). San Francisco: Jossey-Bass.

Dennison, B., Straus, J., Mellits, E., \& Charney, E. (1988). Childhood physical fitness tests: Predictor of adult physical activity levels? Pediatrics, 82, 324-330.

Dielman, T., Leech, S., Becker, M., Rosenstock, I., Horvath, W., \& Radius, S. (1980). Dimensions of children's health beliefs. Health Education Quarterly, 7, 219-238.

Dietz, W., \& Gortmaker, S. (1985). Do we fatten our children at the television set? Obesity and television viewing in children and adolescents. Pediatrics, 75, 805-812.

Bishman, R. (1987). Exercise adherence and habitual physical activity. In W. Morgan \& S. Goldston (Eds.), Exercise and mental health (pp. 57-83). Washington, DC: Hemisphere Publishing.

Dishman, R., Sallis, J., \& Orenstein, D. (1985). The determinants of physical activity and exercise. Public Health Reports, 100, 158-171.

Duncan, B., Boyce, T., Itgami, R., \& Paffenbarger, N. (1983). A controlled trial of a physical fitness program for fifth grade students. Journal of School Health, 53, 467-471.

Duquin, M. (1986). Social comparison and expectancy of success in a sport context. Journal of Sport Behavior, 9, 101-115.

Eiser, C., Walsh, S., \& Eiser, J. (1986). Young children's understanding of smoking. Addictive Behaviors, 11, 119-123.

Evans, R., Rozelle, R., Mittlemark, M., Hansen, W., Bane, A., \& Havis, J. (1978). Deterring the onset of smoking in children: Knowledge of immediate physiological effects and coping with peer pressure, media pressure, and parent modeling. Journal of Applied Social Psychology, 8 , $126-135$.

Folkins, C., \& Sime, W. (1981). Physical fitness training and mental health. American Psychologist, 36, 373-389.

Gaines, L., Brooks, P., Maisto, S., Dietrich, M., \& Shagena, M. (1988). The development of children's knowledge of alcohol and the role of drinking. Journal of Applied Developmental Psychology, 9, 441-457.

Gellert, E. (1962). Children's conception of the content and functions of the human body. Genetic Psychology Monographs, 65, 293-401.

Gochman, D. (1971). Some correlates of children's health beliefs and potential health behavior. Journal of Health and Social Behavior, 12, 148-154.

Godin, G., \& Shephard, R. (1984). Normative beliefs of school children concerning regular exercise. Journal of School Health, 54, 443-445.

Haskell, W., Montoye, H., \& Orenstein, D. (1985). Physical activity and exercise to achieve healthrelated physical fitness components. Public Health Reports, 100, 202-212.

Horn, T., \& Hasbrook, C. (1986). Informational components influencing children's perceptions of their physical competence. In M. Weiss \& D. Gould (Eds.), Sport for children and youth: Proceedings of the 1984 Olympic Scientific Congress (pp. 81-88). Champaign, IL: Human Kinetics.

Maccoby, E., \& Jacklin, C. (1978). The psychology of sex differences. Stanford, CA: Stanford University Press.

Nagy, M. (1953). Children's conceptions of some bodily functions. Journal of Genetic Psychology, $22,359-378$.

Natapoff, J. (1982). A developmental analysis of children's ideas of health. Health Education Quarterly, 9, 130-141.

Peters, B. (1978). School-aged children's beliefs about the causality of illness: A review of the literature. Maternal-Child Nursing Journal, 7, 143-154.

Powell, K., \& Dysinger, W. (1987). Childhood participation in organized school sports and physical 
education as precursors of adult physical activity. American Journal of Preventive Medicine, 3, 276-281.

Reiff, G., Dixon, W., Jacoby, D., Ye, G.X., Spain, C., \& Hunsicker, P. (1986). The President's Council on Physical Fitness and Sports 1985: National School Population Fitness Survey (U.S. Department of Health and Human Services). Washington, DC: U.S. Government Printing Office.

Ross, J., Pate, R., Delpy, L., Gold, R., \& Svilar, M. (1987). The National Children and Youth Fitness Study II: New health-related fitness norms. Journal of Physical Education, Recreation, and Dance, 58(9), 66-70.

Rudisill, M. (1988). Sex differences in various cognitive and behavioral parameters in a competitive situation. International Journal of Sport Psychology, 19, 296-310.

Sallis, J. (1987). A commentary on children: A public health perspective. Research Quarterly for Exercise and Sport, 58, 326-330.

Shantz, C.U. (1983). Social cognition. In P. Mussen (Series Ed.), J. Flavell \& E. Markman (Eds.), Handbook of child psychology: Vol. 3. Cognitive development (pp. 495-555). New York: Wiley.

Siscovick, D., LaPorte, R., \& Newman, J. (1985). The disease-specific benefits and risks of physical activity and exercise. Public Health Reports, 100, 180-188.

Smith, P., \& Remington, P. (1989). The epidemiology of drinking and driving: Results from the Behavioral Risk Factor Surveillance System, 1986. Health Education Quarterly, 16, 345358.

Stone, E., Perry, C., \& Luepker, R. (1989). Synthesis of cardiovascular behavior research for youth health promotion. Health Education Quarterly, 16, 155-169.

Taylor, C., Sallis, J., \& Needle, R. (1985). The relation of physical activity and exercise to mental health. Public Health Reports, 100, 195-202.

Telama, R., Voulle, P., \& Laasko, L. (1981). Health and physical fitness as motives for physical activity among Finnish urban adults. International Journal of Physical Education, 18, 11-16.

Tucker, L. (1986). The relationship of television viewing to physical fitness and obesity. Adolescence, $21,797-806$.

Vealey, R. (1988). Sport-confidence and competitive orientation: An addendum on scoring procedures and gender differences. Journal of Sport and Exercise Psychology, 10, 471-478.

Watkins, B., \& Montgomery, A. (1989). Conceptions of athletic excellence among children and adolescents. Child Development, 60, 1362-1372. 